\title{
Significant blockade of multiple receptor tyrosine kinases by MGCD516 (Sitravatinib), a novel small molecule inhibitor, shows potent anti-tumor activity in preclinical models of sarcoma
}

\author{
Parag P. Patwardhan ${ }^{1, *}$, Kathryn S. Ivy ${ }^{1, *}$, Elgilda Musi ${ }^{1}$, Elisa de Stanchina ${ }^{2}$, \\ Gary K. Schwartz ${ }^{1,3}$ \\ ${ }^{1}$ Herbert Irving Comprehensive Cancer Center, Columbia University, New York, NY, USA \\ ${ }^{2}$ Department of Molecular Pharmacology and Chemistry, Memorial Sloan Kettering Cancer Center, New York, NY, USA \\ ${ }^{3}$ Department of Medicine, Division of Hematology/Oncology, Columbia University Medical Center, New York, NY, USA \\ *These authors have contributed equally to this work \\ Correspondence to: Parag P. Patwardhan, e-mail: ppp2115@cumc.columbia.edu \\ Keywords: MGCD516, Sitravatinib, tyrosine kinase, imatinib, crizotinib \\ Received: September 03, $2015 \quad$ Accepted: November 25, $2015 \quad$ Published: December 10, 2015
}

\section{ABSTRACT}

Sarcomas are rare but highly aggressive mesenchymal tumors with a median survival of 10-18 months for metastatic disease. Mutation and/or overexpression of many receptor tyrosine kinases (RTKs) including c-Met, PDGFR, C-Kit and IGF1-R drive defective signaling pathways in sarcomas. MGCD516 (Sitravatinib) is a novel small molecule inhibitor targeting multiple RTKs involved in driving sarcoma cell growth. In the present study, we evaluated the efficacy of MGCD516 both in vitro and in mouse xenograft models in vivo. MGCD516 treatment resulted in significant blockade of phosphorylation of potential driver RTKs and induced potent anti-proliferative effects in vitro. Furthermore, MGCD516 treatment of tumor xenografts in vivo resulted in significant suppression of tumor growth. Efficacy of MGCD516 was superior to imatinib and crizotinib, two other well-studied multi-kinase inhibitors with overlapping target specificities, both in vitro and in vivo. This is the first report describing MGCD516 as a potent multi-kinase inhibitor in different models of sarcoma, superior to imatinib and crizotinib. Results from this study showing blockade of multiple driver signaling pathways provides a rationale for further clinical development of MGCD516 for the treatment of patients with soft-tissue sarcoma.

\section{INTRODUCTION}

Sarcomas are a heterogeneous group of rare tumors arising from embryonic mesodermal origin and presenting as soft tissue and bone tumors [1,2]. Despite making up only about $1 \%$ of all cancer cases each year (about 14,000 cases), there are more than 50 currently characterized types $[1,3-5]$. The most common sarcomas include leiomyosarcoma (20\%), liposarcoma (17\%) and synovial sarcoma (14\%) [6]. Other rare sarcomas, such as malignant peripheral nerve sheath tumor, have an incidence rate of about 5\% [7]. First line of treatment for localized disease is surgical resection followed by radiotherapy with or without adjuvant chemotherapy. Metastatic disease, however, requires intensive chemotherapy with great toxicity and generally inadequate efficacy, leading to a median survival from diagnosis of 10-18 months [8].
Recent understanding of genomic markers and driver kinases in sarcoma has contributed to the advances in sarcoma therapy with moderate success [9]. Targeted therapies have been employed in many subtypes, particularly in liposarcomas and gastrointestinal stromal tumors (GIST) [10, 11]. CDK4, a cytosolic kinase involved in cell cycle progression, is amplified in greater than $90 \%$ of liposarcoma cases. A recent clinical trial of Palbociclib, a selective CDK4 inhibitor, produced a favorable progression-free survival rate in liposarcoma [12]. Similar strategies using small molecule inhibitors and antibody-based therapy against receptor tyrosine kinases (RTKs) have been used with some success in solid tumors [13] including sarcomas [14, 15]. Imatinib mesylate, the first line of therapy for GIST, is a tyrosine kinase inhibitor (TKI) targeted toward c-Kit, c-Abl, and PDGFR, well-characterized oncogenic RTKs. Genotyping 
GIST allows for directed therapies depending on c-KIT and PDGFR mutational status [10]. The response rates for these targeted therapies are encouraging and pave the way for the development of more specific therapies.

RTKs are key regulators of tumor development as well as metastasis, aiding in the epithelial-mesenchymal transition, migration and angiogenesis. RTK signaling pathways such as VEGFR, PDGFR, and c-Met have been shown to be critical for cell survival, proliferation and metastasis in sarcomas $[9,14]$. Current therapies have evolved from single tyrosine kinase inhibitors (TKIs) such as Bevacizumab [16] to angiokinase inhibitors targeting VEGFR in addition to kinases such as PDGFR and c-Kit, such as sunitinib, sorafenib [17] and BIBF1120 [18]. Even though TKIs have been used with moderate success to block tumor cell survival and proliferation, activation of compensatory signaling pathways gives rise to drug resistance in a majority of cases $[19,20]$. There is an unmet need for potent multi-targeted kinase inhibitors that may help overcome intrinsic and/or acquired resistance to the traditional targeted therapies.

This present study is the first report describing the in vitro and in vivo efficacy of MGCD516, a novel, broad spectrum small molecule inhibitor that blocks a wide array of RTKs known to be amplified/overexpressed in sarcomas, including c-Kit, PDGFR $\beta$ [21], PDGFR $\alpha$, c-Met, and Axl [9, 19]. Reports of use of other multikinase inhibitors in sarcoma such as imatinib have not been very encouraging [22] or restricted to a smaller patient sub-population such as use of crizotinib in ALK driven tumors [23]. We tested the efficacy of MGCD516 using a wide panel of sarcoma cell lines, including malignant peripheral nerve sheath tumor (MPNST), Ewing sarcoma (A673), osteosarcoma (Saos2), and liposarcoma (DDLS, LS141). Both in vitro and in vivo efficacy of MGCD516 was significantly better that the other two multi-kinase inhibitors, imatinib and crizotinib. MGCD516 treatment not only inhibits tumor cell proliferation at low nanomolar concentrations in vitro but also results significant tumor growth suppression in vivo in mouse xenograft models. Our findings strongly suggest further clinical exploration of MGCD516 in patients with soft tissue sarcoma.

\section{RESULTS}

\section{Basal levels of receptor tyrosine kinase (RTK) expression varies among different sarcoma cell lines}

Many sarcoma subtypes are characterized by potential driver kinases such as c-Met, IGF1-R, PDGFR $\alpha$, and c-Kit [9]. To confirm the complexities of sarcoma receptor tyrosine kinase (RTK) signaling, we determined the basal expression levels of RTKs using western immunoblotting in seven different sarcoma cell lines. The
RTKs tested included kinases from PDGFR, IGFR, Ephrin (Eph), VEGFR and c-Met family among others. The cell lines tested represent osteosarcoma (Saos2), Ewing sarcoma (A673, CHP100), liposarcoma (DDLS, LS141), malignant peripheral nerve sheath tumor (MPNST), and synovial sarcoma (SYO-1). Based on the results of the preliminary data, we decided to include five cell lines for further studies that showed basal expression levels for the most number of receptor tyrosine kinases (Supplementary Table S1). All five cell lines showed expression of EphA1, EphB4 and VEGFR1 whereas expression levels of kinases from other RTK families varied among different cell lines (Figure 1A). While both liposarcoma cell lines (DDLS and LS141) showed high levels of IGF1-R expression, only MPNST cell line showed significant levels of PDGFR $\alpha$ expression (Figure 1A). We next tested the basal phosphorylation levels of RTKs in these five cell lines grown in $10 \%$ FBS containing media using phospho-RTK proteome profiler kit (R\&D Systems, ARY001B). Among the cell lines tested, A673, LS141 and Saos2 showed high levels of phospho-IGF1-R, whereas, only two cell lines (DDLS and MPNST) showed high basal phosphorylation levels of c-Met (Figure 1B). Higher auto-radiographic exposures showed presence of basal phosphorylation levels of Eph (Ephrin) receptor kinases as well especially in the cell lines A673 and MPNST (Supplementary Figure S1). Even though we were able to detect basal levels of expression (Figure 1A) and phosphorylation of RYK (Figure 1B), an orphan atypical kinase related to RTKs, it is highly unlikely that it plays any significant role in driving sarcoma cell growth especially since it lacks any catalytic activity of its own [24]. However, it has been shown to be phosphorylated by Eph family of receptors [24]. Taken together, there were multiple potential driver kinases for each cell line with varying degrees of basal expression and phosphorylation levels. The most common RTKs with high basal expression levels in the sarcoma cell lines tested were IGF1-R, c-Kit, c-Met and PDGFRb (Figure 1A). These are also known to be the more canonical sarcoma driver kinases [21, 25, 26].

\section{MGCD516 is a novel broad-spectrum RTK inhibitor and has potent anti-proliferative effects}

Figures 1A and 1B clearly indicate the complexity of signaling pathways in sarcoma cells and demonstrate the need for therapies that target multiple RTKs. MGCD516 is a potent broad-spectrum RTK inhibitor (Figure 1C) with multiple targets including Axl, c-Met, Ephrin receptor family (EphA1, A2, B1, B2, B4), as well as PDGFR and VEGFR family of kinases (Table 1). Many of the targets inhibited by MGCD516 are among the known potential driver kinases in sarcoma [9]. Therefore, we explored anti-proliferative effect of MGCD516 in five sarcoma cell lines used in Figure 1. As shown in Figure 2A, all the cell lines tested were sensitive to increasing 

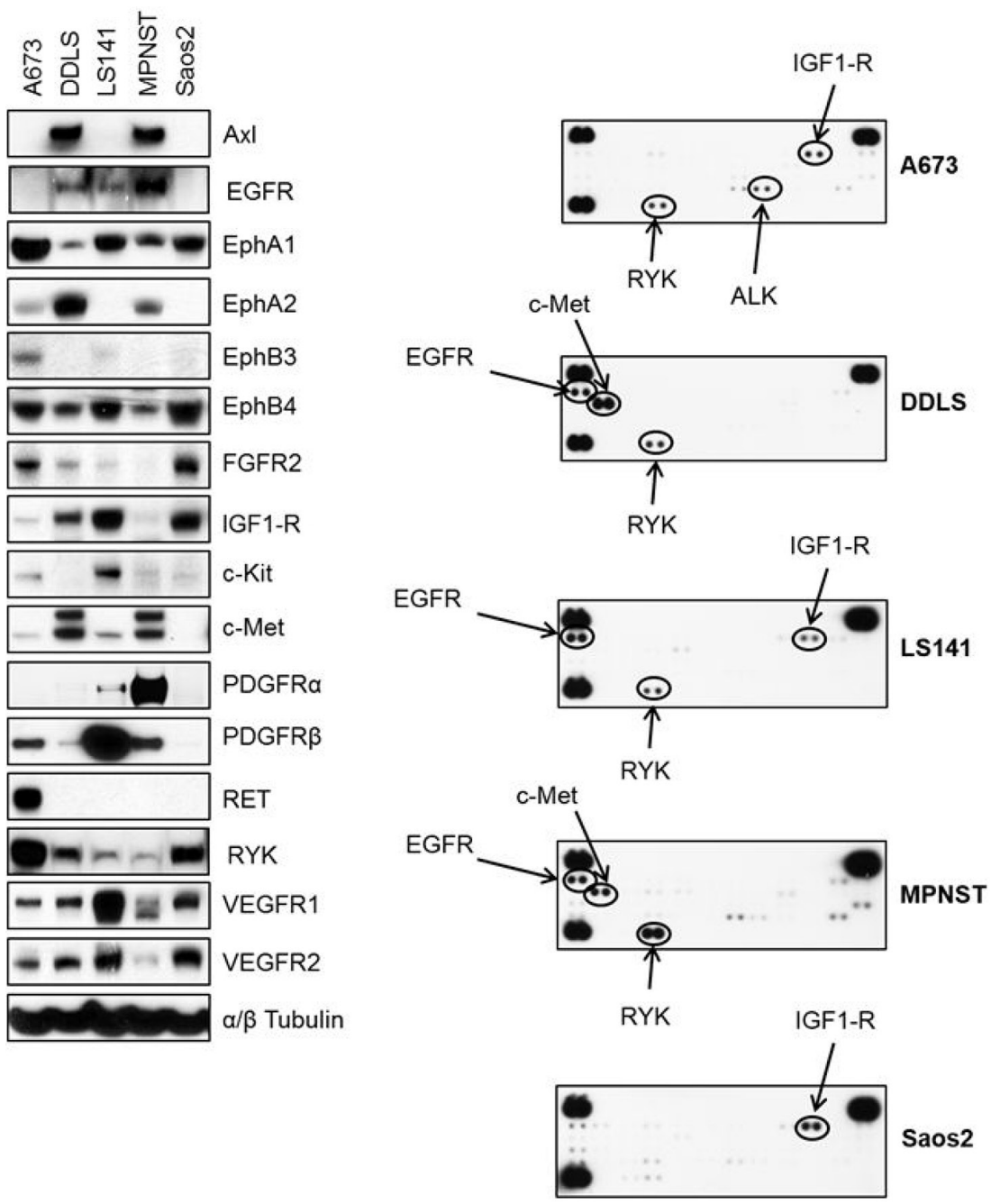

C

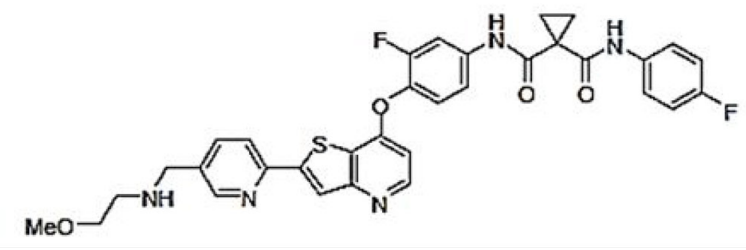

Figure 1: Basal levels of total and phosphorylated receptor tyrosine kinases in five sarcoma cell lines. A. Approximately, $1 \times 10^{6}$ cells were plated in $60 \mathrm{~mm}$ plates in media containing $10 \% \mathrm{FBS}$ and grown for 24 hours. Next day, 30 micrograms of RIPA lysates were loaded on SDS/PAGE and immunoblotted using indicated antibodies. B. $1 \times 10^{6}$ cells were plated in $60 \mathrm{~mm}$ plates for 24 hours in media containing 10\%FBS. Next day, lysates were prepared according to manufacturer's instructions (R\&D Systems, ARY001B) and 200 micrograms of lysates were applied to phospho-RTK membranes overnight at $4^{\circ} \mathrm{C}$. Arrows indicate phosphorylated RTK spots in duplicate. C. MGCD516 (Sitravatinib) is a novel, potent multi-kinase small molecule inhibitor. Chemical structure of MGCD516 is shown.

concentrations of MGCD516 with three cell lines, DDLS, LS141 and MPNST, showing greater inhibition of proliferation at low nanomolar concentrations than the other two cell lines (A673, Saos2). The $\mathrm{IC}_{50}$ values for the three sensitive cell lines (DDLS, MPNST and LS141) ranged between $250-750 \mathrm{nmol} / \mathrm{L}$, whereas, $\mathrm{IC}_{50}$ values 
Table 1: In vitro kinase inhibition profile of MGCD516 (Sitravatinib)

\begin{tabular}{|c|c|}
\hline RTK target & Biochemical $\left(\mathrm{IC}_{50} \mathrm{nmol} / \mathrm{L}\right)$ \\
\hline Axl & 1.5 \\
\hline MER & 2 \\
\hline MET & 20 \\
\hline VEGFR2 (KDR) & 5 \\
\hline VEGFR1 (FLT1) & 6 \\
\hline VEGFR3 (FLT4) & 2 \\
\hline FLT3 & 8 \\
\hline KIT & 6 \\
\hline PDGFR $\alpha$ & 30 \\
\hline PDGFR $\beta$ & ND \\
\hline DDR1 & 29 \\
\hline DDR2 & 0.5 \\
\hline RET & 44 \\
\hline TRKA (NTRK1) & 5 \\
\hline TRKB (NTRK2) & 9 \\
\hline EPHA2 & 44 \\
\hline EPHA3 & 1 \\
\hline EPHA4 & 76 \\
\hline EPHB2 & 10 \\
\hline EPHB4 & 12 \\
\hline FYN & 339 \\
\hline $\mathrm{RON}$ & 43 \\
\hline ROS & 59 \\
\hline SRC & 156 \\
\hline TIE2 & 274 \\
\hline YES & 298 \\
\hline PYK2 & 364 \\
\hline BTK & 304 \\
\hline EPHB3 & 249 \\
\hline INSR & 5550 \\
\hline $\mathrm{HCK}$ & 1109 \\
\hline FER & 1589 \\
\hline LTK & 1938 \\
\hline FES & 2010 \\
\hline FMS & 2290 \\
\hline $\mathrm{ABL}$ & 2987 \\
\hline
\end{tabular}




\begin{tabular}{|c|c|}
\hline RTK target & Biochemical $\left(\mathrm{IC}_{50} \mathrm{nmol} / \mathrm{L}\right)$ \\
\hline IGF1R & 3980 \\
\hline ARG & 4098 \\
\hline FGFR1 & $>5000$ \\
\hline FGFR2 & $>5000$ \\
\hline FGFR3 & $>5000$ \\
\hline FGFR4 & $>5000$ \\
\hline ITK & $>5000$ \\
\hline ERBB1 & $>5000$ \\
\hline ERBB2 & $>5000$ \\
\hline ERBB4 & $>5000$ \\
\hline EPHA1 & $>10000$ \\
\hline EPHB1 & $>10000$ \\
\hline FAK & $>10000$ \\
\hline JAK1 & $>10000$ \\
\hline JAK2 & $>10000$ \\
\hline JAK3 & $>10000$ \\
\hline ALK & $>10000$ \\
\hline SYK & $>10000$ \\
\hline ZAP70 & $>10000$ \\
\hline
\end{tabular}

for the less sensitive cell lines (A673 and Saos2) ranged between 1.5-2.0 mmol/L (Supplementary Table S2). Next we tested the inhibition of RTK signaling by MGCD516 using western immunoblotting by treating the cells with increasing concentrations of the drug. Figure 2B shows complete inhibition of phosphorylation of the targets including c-Met, IGF1-R, and PDGFRb at low nanomolar concentrations ranging from $60-500 \mathrm{nmol} / \mathrm{L}$. In addition to the down-regulation of RTK phosphorylation, we also observed significant down-regulation of p-AKT (Ser473) with increasing concentrations of MGCD516 (Figure 2B).

In order to confirm blockade of phosphorylation of multiple RTKs by MGCD516, we next carried out phospho-RTK proteome profiler array analysis. MGCD516 treatment resulted in significant down-regulation of RTK phosphorylation including the canonical RTKs PDGFRa, PDGFR $\beta$, IGF1-R and c-Met (Figure 3). There was also a marked reduction in phosphorylation of RTKs such as Axl and ALK which have also been reported as potential driver kinases in sarcoma [9]. Interestingly, MGCD516 demonstrated inhibition of RTKs including IGF1R and ALK that were not potently inhibited in RTK enzymatic assays (Table 1) suggesting that the inhibitory effects observed for these kinases may be mediated via heterodimerization with direct RTK targets of MGCD516 such as c-Met [27].

Results from cell proliferation, western immunoblotting as well as phospho-RTK array analysis confirmed that MGCD516 is a broad-spectrum multikinase inhibitor that results in potent anti-proliferative effects as well as significant down-regulation of its targets at low nanomolar concentrations in vitro.

\section{MGCD516 is superior to other multi-kinase inhibitors in inhibiting cell proliferation, RTK phosphorylation, and phosphorylation of downstream effectors in vitro}

Next, we compared MGCD516 against other multi-kinase inhibitors, which have overlapping target specificity. First, we evaluated the efficacy of MGCD516 in the three sensitive cell lines (DDLS, LS141 and MPNST) against pazopanib, a drug recently approved for the treatment of sarcoma [28]. Our results (Figure 4A) showed that MGCD516 treatment was able to inhibit proliferation of LS141 and DDLS cell lines significantly better than pazopanib especially at $1000 \mathrm{nM} / \mathrm{L}$ concentration $(p<0.0005)$ suggesting better pathway inhibition by MGCD516. Inhibition of MPNST cell proliferation was similar for pazopanib and MGCD516 (Figure 4A) given the ability of both pazopanib and MGCD516 to inhibit PDGFR and c-Kit, the two main RTKs driving MPNST cell proliferation [29]. Next, we determined the efficacy of MGCD516 
A

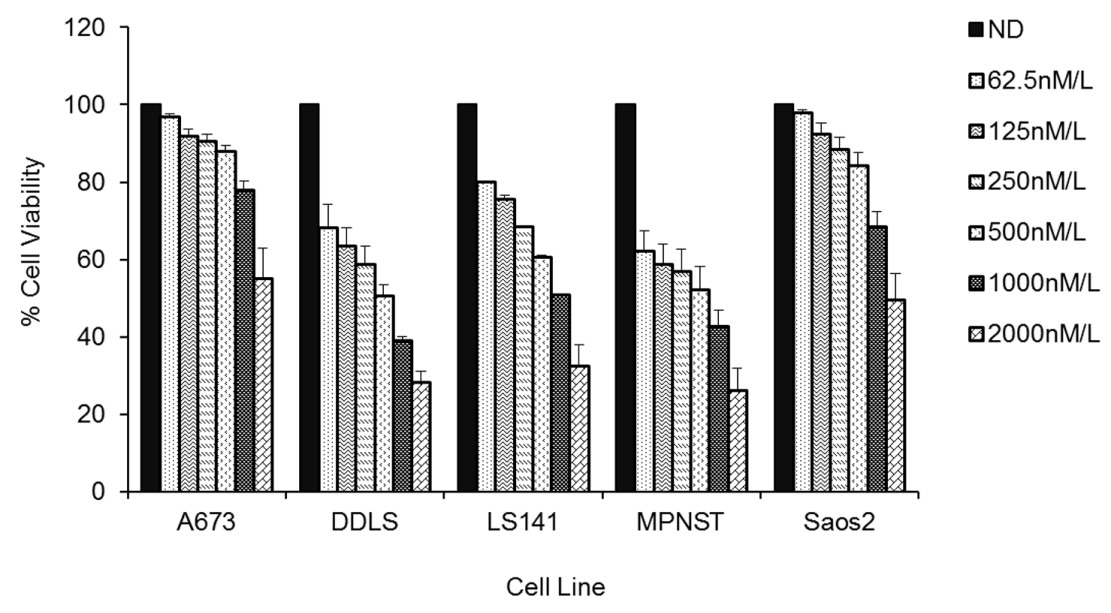

B
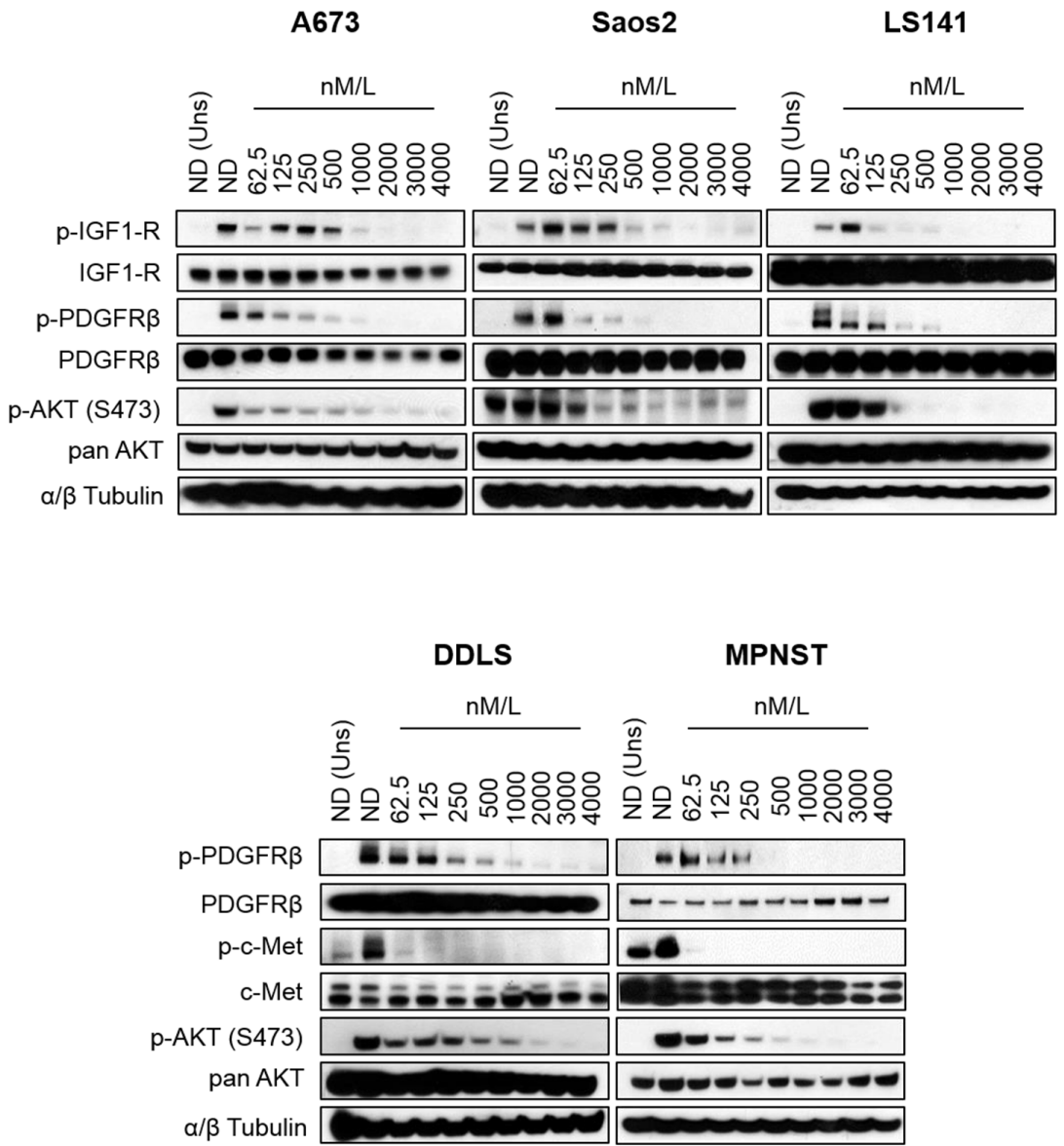

Figure 2: MGCD516 has potent anti-proliferative effect and inhibits multiple RTKs at low nanomolar concentrations. A. Indicated cell lines were plated in 96-well plates and treated in six wells per condition with increasing doses of MGCD516 for 72 hours. Cell viability was measured using Dojindo Cell Counting Kit 8. Dose response graphs were generated as a percentage of the no drug control. Error bars represent standard error mean. Combined data from three independent experiments is shown. B. Indicated cell lines were grown to $60 \%$ confluency in serum free media overnight. Next day, cells were treated with indicated concentrations of MGCD516 in serum free media for 3 hours. After the drug treatments, cells were stimulated in drug free media containing 10\%FBS. Media containing no FBS was used as unstimulated control. 20 to 30 micrograms of RIPA lysates were loaded on SDS/PAGE and immunoblotted using indicated antibodies. Representative western blots from two independent experiments are shown. ND=No Drug, Uns=Unstimulated control. 
against crizotinib, an ALK and c-Met inhibitor, and imatinib, a PDGFR and c-Kit inhibitor. Based on the $\mathrm{IC}_{50}$ value determination (Supplementary Table $\mathrm{S} 2$ ), we decided to use $500 \mathrm{nmol} / \mathrm{L}$ of all the tyrosine kinase inhibitors (TKIs). Treatment with MGCD516 showed significant inhibition of proliferation as compared to crizotinib in all the three cell lines tested $(p<0.005)$ (Figure 4B). In MPNST, treatment with imatinib showed anti-proliferative effect similar to MGCD516 again highlighting the role of c-Kit and PDGFR as driver kinases in this cell line as has been reported previously [29]. For all three cell lines tested, combined treatment with imatinib and crizotinib showed similar anti-proliferative effect as that of MGCD516 (Figure 4B) strongly indicating that MGCD516 is efficient in blocking multiple RTKs that the other two drugs block individually.

Western blot analysis comparing MGCD516 against imatinib and crizotinib either alone or in combination, in the two sensitive cell lines DDLS and MPNST, showed that MGCD516 was efficient in blocking multiple RTKs and showed significantly better inhibition of downstream effectors such as p-AKT (Ser473) than the other two drugs (Figure 4C). We also compared the efficacy of MGCD516 against imatinib and crizotinib using a colony formation assay as a measure of tumorigenicity. In MPNST cell line, treatment with MGCD516 at $500 \mathrm{nmol} / \mathrm{L}$, concentration similar to the one used for cell proliferation assay comparisons, resulted in significant reduction in colony number compared to no drug control as well as compared to imatinib and crizotinib treatment alone $(p<0.05$, Figure 4D). Similar to the results obtained in Figure 4B, effect of imatinib and crizotinib combination treatment was comparable to MGCD516 alone (Figure 4D). Furthermore, comparison against two structurally similar drugs, carbozantinib [30] and foretinib [31], showed that MGCD516 had a significantly higher anti-proliferative effect ( $p<0.05$, Supplementary Figure S2A).

Many small-molecule RTK inhibitors including sorafenib and lapatinib have been considered as cytostatic agents rather than cytotoxic drugs [32]. To test whether the inhibition of cell proliferation by MGCD516 is due to cytostatic rather than cytotoxic effects, we carried out flow cytometry cell-cycle analysis after MGCD516 treatment in MPNST cell line. Treatment with increasing concentrations of MGCD516 induced a significant G1 cell-cycle arrest (Supplementary Figure S2B, left panel). Down-regulation of cyclin D1 has been reported to play a role in G1 cell-cycle arrest in other cancer cell lines [33]. Western blot analysis after treatment with MGCD516 induced significant down-regulation of cyclin D1 and a significant decrease in hyperphosphorylated form of retinoblastoma protein $(\mathrm{p}-\mathrm{Rb})$ but no induction of cleaved PARP was seen (Supplementary Figure S2B, right panel) thus indicating that MGCD516 is a cytostatic than a cytotoxic drug.

Considering the complexities of signaling pathways in sarcoma, we also tested MGCD516 in combination with doxorubicin, a commonly used chemotherapeutic agent. Combination treatment with doxorubicin, at two different concentrations, $10 \mathrm{nM} / \mathrm{L}$ and $100 \mathrm{nM} / \mathrm{L}$ did not show any significant inhibition of cell proliferation by MGCD516 compared with MGCD516 treatment alone (Supplementary Figure S2C).

\section{Inhibitory effect of MGCD516 can be replicated by siRNA mediated knockdown of multiple RTKs}

In order to confirm the role played by potential driver RTKs in each of the three cell lines (DDLS, LS141 and MPNST), we next carried out siRNA mediated knockdown of these kinases either alone or in combination and compared the anti-proliferative effect against MGCD516 treatment. While DDLS and MPNST showed higher basal levels of c-Met and PDGFR $\beta$ (Figure 1A), LS141 cell line showed high basal levels of IGF1-R and PDGFR $\beta$. Therefore, we carried out siRNA mediated knockdown of c-Met and PDGFR $\beta$ in DDLS and MPNST and IGF1-R and PDGFR $\beta$ in LS141 either alone or in combination. Transfection using pooled siRNAs resulted in almost complete knockdown of protein expression (Figure 5A, 5B, 5C and 5D, right panel). Cell viability assays clearly showed that siRNA mediated combined knockdown of the potential driver kinases had a significant anti-proliferative effect compared to scrambled siRNA in all the three cell lines tested $(p<0.005)$ (Figure 5A, 5B, $5 \mathrm{C}$ and $5 \mathrm{D}$, bar graphs). This anti-proliferative effect was comparable to MGCD516 treatment strongly suggesting that blockade of RTK phosphorylation by MGCD516 is comparable to blockade achieved using siRNA mediated knockdown. For MPNST cell line, combined knockdown of c-Met and PDGFR $\beta$ showed lesser anti-proliferative effect (Figure 5B), however, as shown previously [29], combined knockdown of PDGFR $\beta$ and c-Kit resulted in similar anti-proliferative effect as that of MGCD516 (Figure 5C) suggesting a role of these two RTKs in driving MPNST cell proliferation. Also, for LS141 cell line, combined blockade of IGF1-R and PDGFR $\beta$, showed significantly higher anti-proliferative effect than 500 $\mathrm{nmol} / \mathrm{L}$ MGCD516 treatment (Figure 4D). This could in part be due to the fact that the drug concentration used $(500 \mathrm{nmol} / \mathrm{L})$ is lower than the $\mathrm{IC}_{50}$ concentration observed for LS141 (Supplementary Table S2) as well as higher biochemical $\mathrm{IC}_{50}$ value noted for IGF1-R (Table 1) in vitro. In addition, as mentioned earlier, IGF1-R may not be a direct target of the drug; instead the effect could be due to blockade of signaling resulting from heterodimerization of IGFR with other RTK targets of MGCD516 [27]. 
DMSO Control

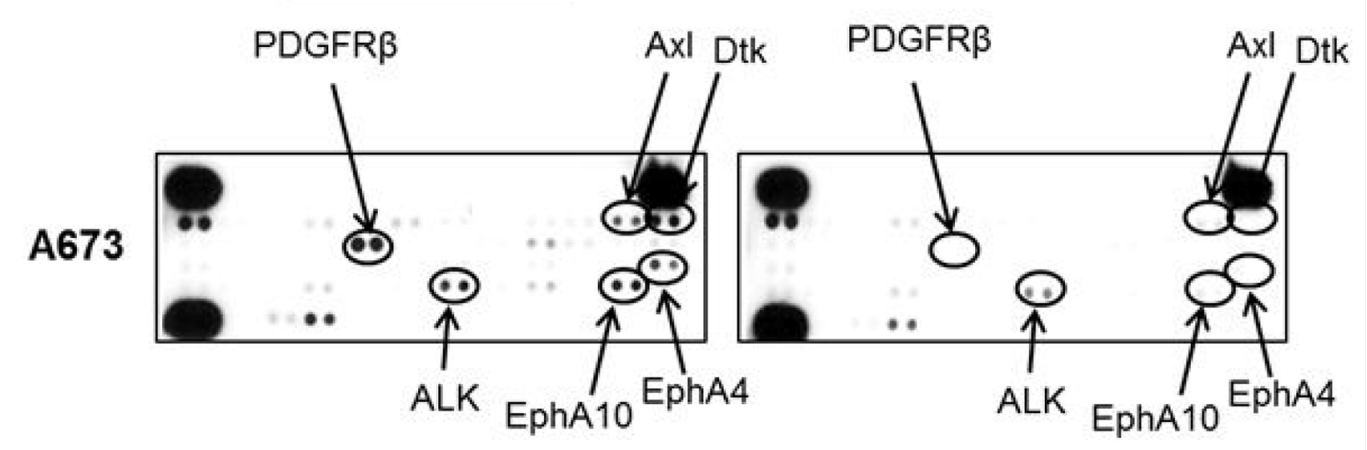

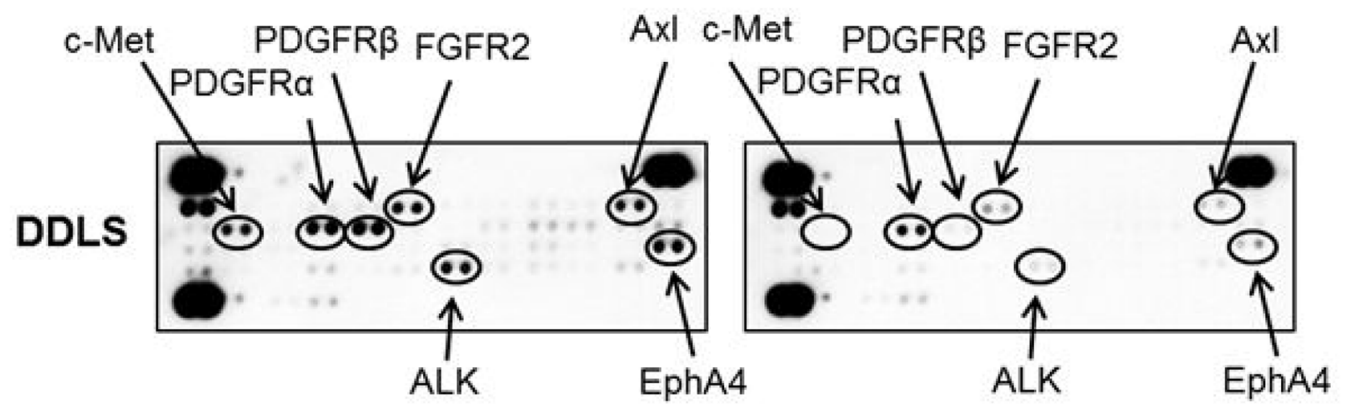
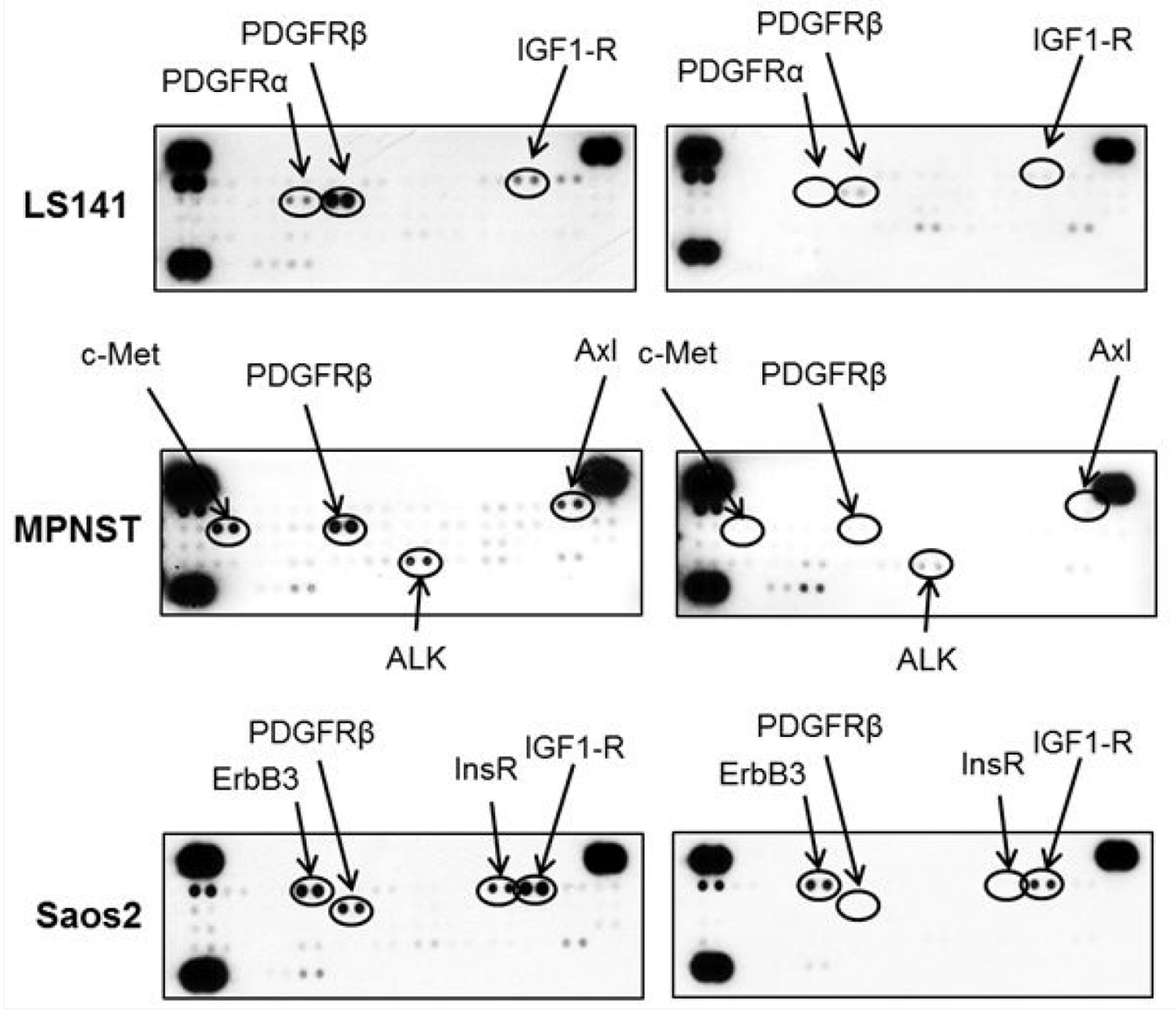

Figure 3: Broad spectrum activity of MGCD516 shows blockade of multiple RTKs across various sarcoma subtypes. Approximately, $1 \times 10^{6}$ cells were plated in $60 \mathrm{~mm}$ plates in serum free media for 24 hours. Next day, DMSO or MGCD516 was added in serum free media and treated for 3 hours. Cells were then stimulated in media containing $10 \%$ FBS for 1 hour. Following stimulation, lysates were prepared according to manufacturer's instructions (R\&D Systems, ARY001B) and 200 micrograms of lysates were applied to phosphoRTK membranes overnight. Arrows indicate phosphorylated RTK spots in duplicate. 
A

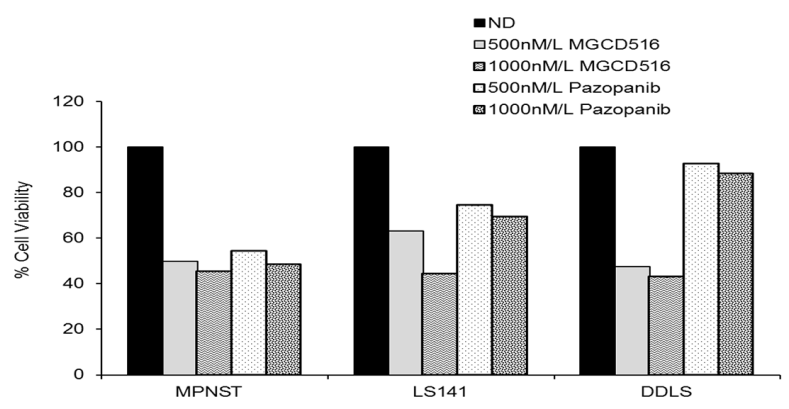

B

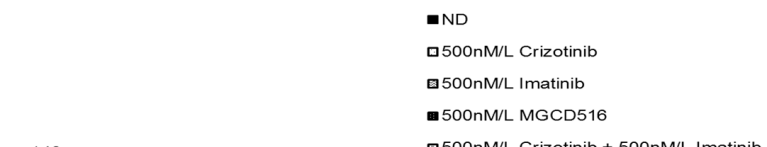

C
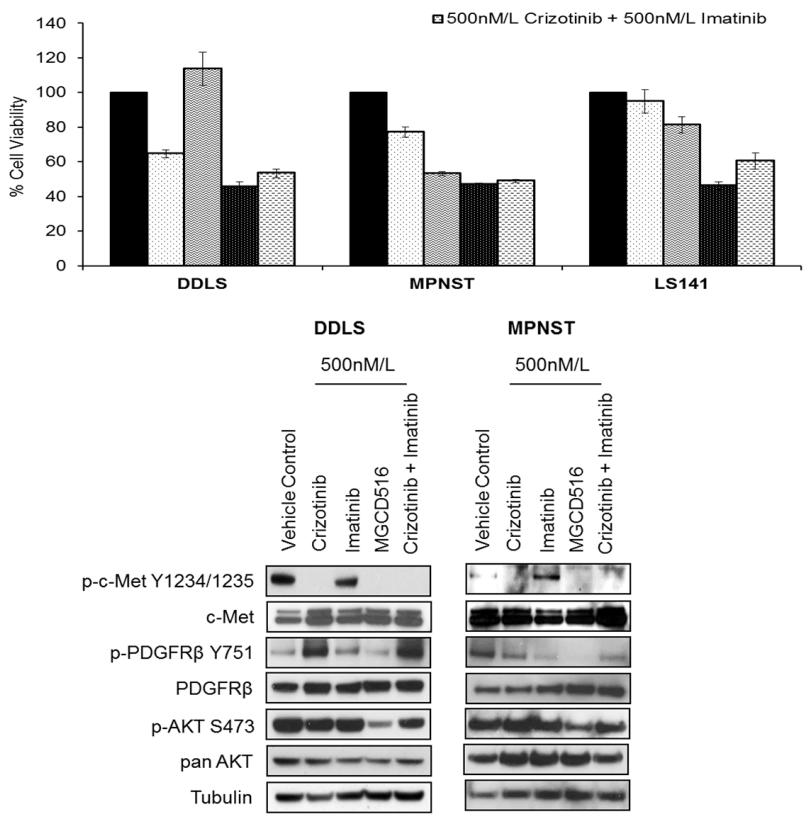

D

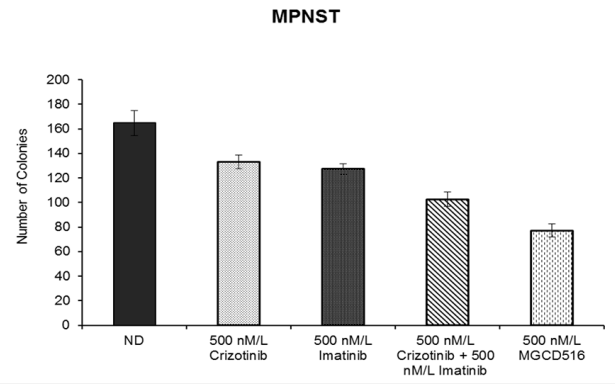

Figure 4: MGCD516 treatment results in superior anti-proliferative effect, better inhibition of downstream targets such as p-AKT and greater reduction in colony growth when compared to imatinib and crizotinib. $\mathbf{A}$. and B. Indicated cell lines were plated in 96-well plates and treated in triplicate with indicated concentrations of drugs for 72 hours. Cell viability was measured using Dojindo Cell Counting Kit 8. Graphs were generated as a percentage of the no drug (ND) control. Error bars represent standard error mean. Combined data from at least two independent experiments is shown. Note: For Figure 4A, error bars are included; however, they are too small to be seen. C. Indicated cell lines were grown to $60 \%$ confluency in serum free media overnight. Next day, cells were treated with indicated concentrations of MGCD516 in serum free media for 3 hours. After the drug treatments, cells were stimulated in drug free media containing 10\%FBS. 30 micrograms of RIPA lysates were loaded on SDS/PAGE and immunoblotted using indicated antibodies. Representative western blots from two independent experiments are shown. D. 1,000 cells were plated, in triplicate, onto $100 \mathrm{~mm}$ dishes and treated the next day with the indicated drugs in media containing $10 \% \mathrm{FBS}$ for 24 hours. Following treatment, cells were cultured in drug-free media for 10 to 14 days. Colonies were scored with ColCount software from Oxford Optronix (Abingdon, UK). Combined data from the experiment carried out in triplicate is shown. 


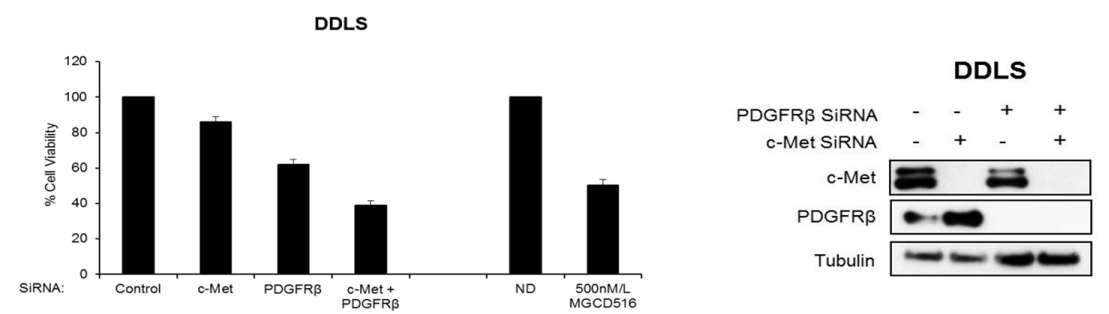

B
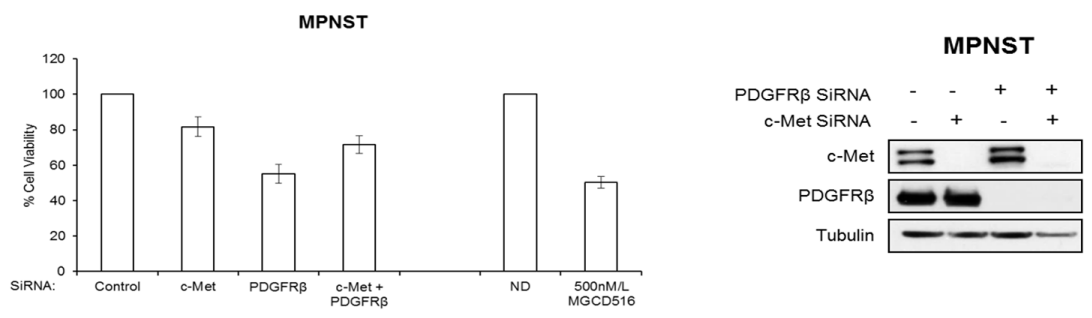

C
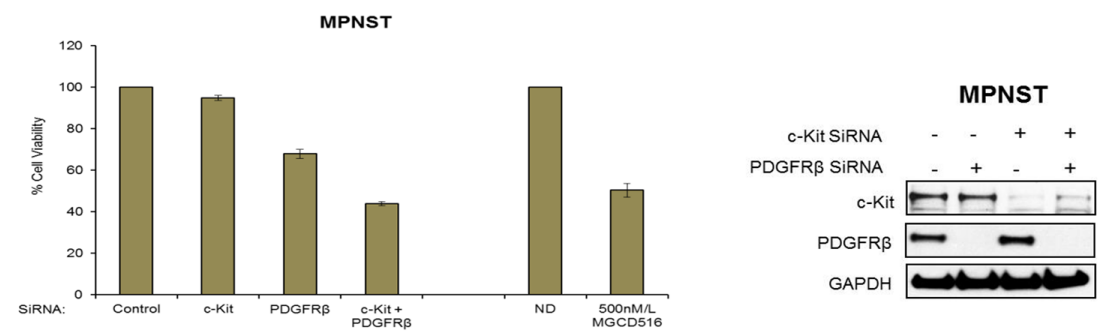

D
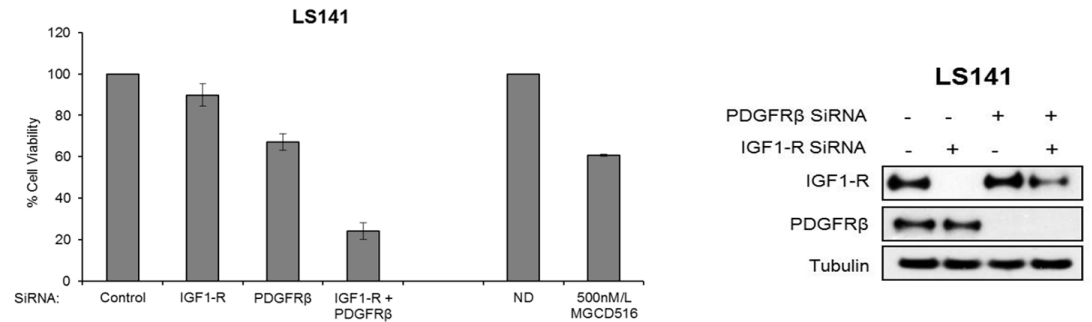

Figure 5: siRNA mediated knockdown of potential driver RTKs results in inhibition of cell proliferation similar to MGCD516 treatment. A, B, C and D. Approximately, 5-7.5 $\times 10^{5}$ cells were plated and transfected with $50 \mathrm{nmol} / \mathrm{L}$ of indicated siRNAs (GE Dharmacon) the same day. 24 hours later, media was changed and cells were transfected again with $50 \mathrm{nmol} / \mathrm{L}$ siRNA. After another 24 hours, cells were harvested and approximately 2000 cells per well were plated in 96 well plates in triplicates. Remaining cells were lysed in RIPA buffer and lysates were used to confirm knockdown of protein expression by western immunoblotting. Cell viability was measured using Dojindo Cell Counting Kit 8. Cell viability assay carried out using MGCD516 treatment at $500 \mathrm{nmol} / \mathrm{L}$ is shown for comparison. Error bars represent standard error mean. Combined data from at least two independent experiments is shown. 


\section{MGCD516 induces significant tumor growth suppression than imatinib and crizotinib in vivo}

Next, we carried out in vivo mouse xenograft experiments using MPNST and LS141 models. In order to be consistent with our in vitro data, we compared MGCD516 treatment against imatinib and crizotinib in vivo. Treatment with any of the drugs including MGCD516 did not result in toxicity as determined by animal weight during the study period (Supplementary Figure S3). In both MPNST and LS141 xenograft experiments, MGCD516 treatment resulted in significant suppression of tumor growth compared to vehicle control $(p<0.0005)$ as well as compared against imatinib and crizotinib (Figure 6A and 6B) $(p<0.005)$. Western blot analysis of tissue samples obtained after 3 weeks of treatment showed greater inhibition of phosphorylation of potential driver kinases such as c-Kit, IGF1-R and PDGFR $\beta$ compared to imatinib and crizotinib as well as significant down-regulation of downstream effector pathways such as p-AKT (Ser473) and p-S6 (Ser235/236) (Figure 6A and 6B). To test the effect of MGCD516 treatment on proliferating tumor cells, we tested Ki67 as a proliferation marker on formalin fixed tumor tissues. Tumor samples treated with MGCD516 for 3 weeks showed significantly less Ki67 staining compared to vehicle control (Figure 6C). Reduction in Ki67 staining indicated strong anti-proliferative effect of MGCD516.

\section{DISCUSSION}

Sarcomas represent a diverse set of malignancies that are difficult to treat given the complexities of various subtypes. Sarcomas are traditionally categorized into two broad categories: tumors with translocations or activating mutations, whereas, the second category includes more complex tumors showing multiple genomic aberrations [34]. Genetically more complex group includes some of the more commonly diagnosed sarcomas such as leiomyosarcoma, and osteosarcoma. Many sarcoma subtypes belonging to both these categories show aberration and/or mutation in signal transduction pathways, particularly defects in receptor tyrosine kinase (RTK) signaling [34, 35]. Recent evidence suggests involvement of RTKs such as PDGFR [29, 36, 37], c-Met [38], Axl [39], IGF1-R [40], EphB4 [41] and ErbB4 [42] as driver kinases in different sarcoma subtypes including synovial sarcoma, Ewing sarcoma as well as malignant peripheral nerve sheath tumor (MPNST). Detailed phosphoproteomic analysis from cell lines and patient tumors also revealed involvement of RTKs such as PDGFR, Eph receptors, Axl, c-Met and IGF1-R [9] as potential driver kinases in sarcomas. Even though RTKs present an attractive therapeutic target [14], in many cases, cells rapidly acquire resistance via compensatory activation and/or mutation of signaling pathways [43]. Therefore, there is an urgent need to develop novel therapeutic agents that will target multiple RTKs in order to block such compensatory signaling pathways thereby preventing development of drug resistance.

MGCD516 is a novel, small molecule inhibitor that has broad spectrum activity against many of the canonical RTKs including c-Met, VEGFR, Axl, Ephrin receptors (Eph), c-Kit and PDGFR. The biochemical $\mathrm{IC}_{50}$ values for many of these RTKs lie in the low nanomolar range (1-200 nmol/L). In the present study, we were able to detect varying levels of expression and phosphorylation of many of the MGCD516 targets such as c-Met, Axl and PDGFR as well as VEGFR and Eph receptors in all five sarcoma cell lines tested. When we evaluated the efficacy of MGCD516 in a cell proliferation assay, we observed increased sensitivity with increasing doses of the drug with $\mathrm{IC}_{50}$ values ranging in the low nanomolar range (250-800 nmol/L) for three out of five cell lines (DDLS, LS141 and MPNST). It must be noted though that two of the five cell lines tested (A673 and Saos2) were less sensitive to inhibition by MGCD516 than the other cell lines. This could probably be due to the fact that A673 cell line, in addition to having high basal expression and phosphorylation levels of many RTKs (IGF1-R, ErbB4, EphA4, EphA10, and ALK), also carries a (BRAF V600E) mutation which could potentially play a role in reduced sensitivity to the drug. For Saos2 cell line, not only were we able to detect lesser number of MGCD516 targets on western blot but also high basal phosphorylation levels of IGF1-R on phospho-RTK array. In vitro $\mathrm{IC}_{50}$ value for IGF1-R inhibition by MGCD516 is much higher (3980 nmol/L) compared to other RTKs such as c-Met (20 $\mathrm{nmol} / \mathrm{L})$ or PDGFR $\alpha(30 \mathrm{nmol} / \mathrm{L})$ indicating that cell lines with IGF1-R as the sole driver kinase may exhibit reduced sensitivity to the drug. Direct inhibition of IGF1-R activity was not seen in the in vitro enzymatic assays, suggesting that the reduction in phosphorylation could be a result of blockade of heterodimerization with other MGCD516 targets such as c-Met [27].

Multi-kinase inhibitors including imatinib, which blocks RTKs such as c-Kit and PDGFR, have been used in sarcoma clinical trials with modest success [22]. Crizotinib, which inhibits c-Met and ALK, is also being tested in clinical trials (Clinical Trial Identifier NCT01524926) for sarcoma. Pazopanib, an antiangiogenic agent, that blocks multiple driver RTKs including c-Kit, VEGFR, PDGFR as well as kinases from FGFR family, was recently approved for the treatment of soft-tissue sarcoma [28, 44]. However, one of the reasons for limited success with such multi-kinase inhibitors is the ability of tumors to activate alternate/escape pathways that are not the primary targets of the drug. MGCD516 is unique in a way that it has broad spectrum activity against many RTKs including c-Met, c-Kit, Axl, PDGFR, and Eph receptors that are known to play a role in driving sarcoma cell growth, and thus, it is able to inhibit many of the internal compensatory pathways. Our studies comparing 
A
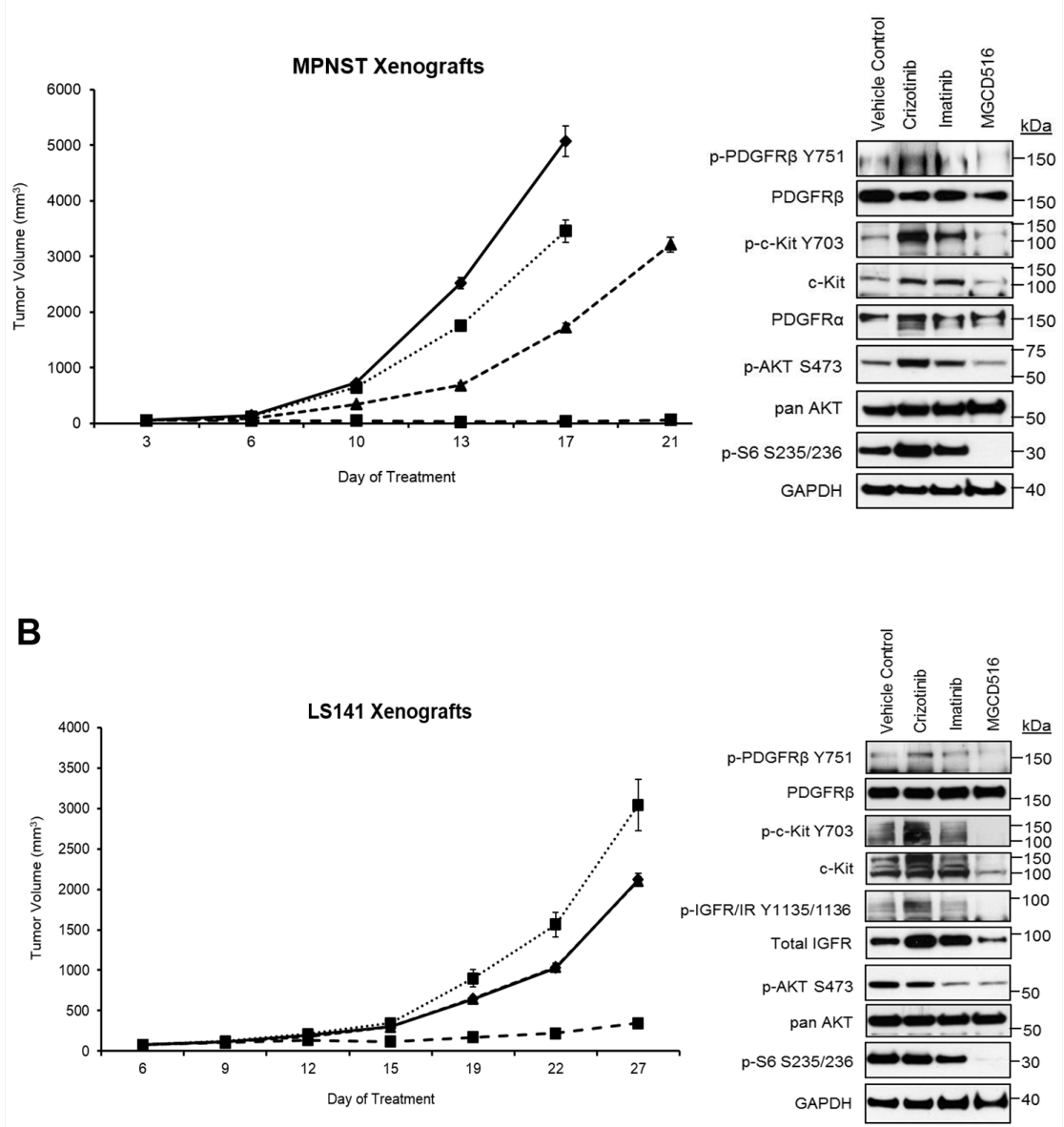

C

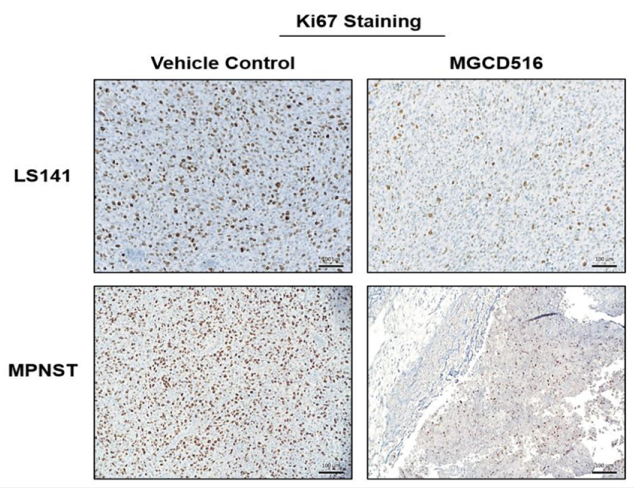

Figure 6: MGCD516 treatment induces significant suppression of tumor growth and better inhibition of downstream targets than imatinib and crizotinib in vivo. A, B. Tumor growth of MPNST and LS141 xenografts treated with the indicated drugs is shown. For MPNST xenografts, treatment was stopped on day 17 for vehicle control and crizotinib treatment group (as the tumors were huge). Note: In the graph for LS141 xenografts, the tumor growth volume lines for vehicle control and imatinib treatment groups are overlapping and therefore not visible as two separate lines. 30 micrograms of RIPA lysates obtained using sample grinding kit (GE Healthcare) from xenograft tissues at the end of 3 week treatment were loaded on SDS/PAGE and immunoblotted using indicated antibodies. C. Xenograft tissues obtained from mice at the end of 3 week treatment with vehicle or MGCD516 were stained immunohistochemically using Ki67 antibody. Scale bar $(100 \mu \mathrm{m})$ is shown in the lower right hand corner of each image. Representative image from at least 2 animals sacrificed at the end of drug treatment is shown. 
MGCD516 against imatinib and crizotinib showed that MGCD516 was clearly superior to the other two drugs in terms of inhibition of cell proliferation as well as blockade of signaling pathways. Interestingly, combination of imatinib and crizotinib showed similar anti-proliferative effect as that of MGCD516 alone strongly suggesting that MGCD516 is able to block multiple RTKs that imatinib and crizotinib block individually.

In the present study, we also carried out silencing of the target RTKs using siRNA mediated approach to verify that blockade of RTK signaling by MGCD516 was indeed responsible for inhibition of cell proliferation in DDLS, LS141, and MPNST cell lines. Combination of siRNAs against potential driver RTKs resulted in comparable inhibition of cell proliferation as that of MGCD516 treatment. In MPNST cell line, combined knockdown of PDGFR $\beta$ and c-Kit but not c-Met resulted in similar antiproliferative effect as that of MGCD516 indicating a role of these two RTKs in driving MPNST cell proliferation as shown previously [29]. In LS141 cell line, siRNA mediated knockdown of IGF1-R and PDGFR $\beta$ resulted in higher inhibition of proliferation than MGCD516 treatment, presumably due to the fact that the $\mathrm{IC}_{50}$ value for IGF1-R inhibition by MGCD516 is much higher than for other kinases. Nevertheless, these results clearly indicate that MGCD516 is efficient in blocking multiple pathways that are critical for sarcoma cell proliferation and this effect can be mimicked by siRNA mediated knockdown of individual RTKs.

Similar to the anti-proliferative effect observed, MGCD516 showed significant inhibition of colony growth and has a greater inhibitory effect on cell colonization than imatinib and crizotinib treatment alone, potentially owing to its greater broad-spectrum activity.

Sustained inhibition of RTKs such as c-Kit and PDGFR has been shown to suppress tumor growth in MPNST [29]. Results from our in vivo data showed that MGCD516 treatment results in significant suppression of tumor growth compared to the other two drugs in both MPNST as well as LS141 xenograft models. Immunohistochemical studies using Ki67 staining as a marker for cell proliferation showed that MGCD516 treatment indeed resulted in decreased cellular proliferation. Western immunoblotting showed that MGCD516 treatment not only resulted in significant blockade of phosphorylation of multiple RTKs such as PDGFR, c-Kit and IGF1-R but also inhibited downstream effectors such as p-AKT and p-S6 which are critical for tumor cell survival and proliferation. Since MGCD516 can inhibit RTKs such as PDGFR and VEGFR, we speculate that the significant tumor suppression achieved in vivo is not only limited to inhibition of signaling pathways in tumor cells but also due to an effect on stromal cell signaling mediated via these kinases. Even though MGCD516 does show inhibition of VEGFR family in vitro, differentiated effects are observed from other more well-studied VEGFR inhibitors such as sunitinib, which do not share additional MGCD516 targets (personal communication with Dr. James Christensen, Mirati Therapeutics). Interestingly, crizotinib treatment in LS141 xenografts showed greater tumor growth than vehicle control perhaps as a result of activation of other RTKs such as increased phospho-c-Kit and phospho-IGF1-R signal seen on western immunoblotting.

Taken together, our data strongly suggest that broad spectrum inhibition of multiple RTK signaling pathways by MGCD516 both in vitro and in vivo results in superior activity compared to imatinib and crizotinib. Significant down-regulation of downstream pathways such as p-AKT and p-S6 also contributed to higher tumor growth suppression in vivo. This is the first pre-clinical report describing MGCD516 (Sitravatinib) as a potent and broad spectrum inhibitor of RTKs. A phase I trial with MGCD516 is already underway and results from this present study can be extended to other RTK driven solid tumors. We believe that our data would support the development of MGCD516 as a potential therapy for patients with soft-tissue sarcoma.

\section{MATERIALS AND METHODS}

\section{Drugs}

MGCD516 (Sitravatinib) was provided by Mirati Therapeutics (San Diego, CA) in the form of powder; it was dissolved in dimethyl sulfoxide (DMSO) for in vitro studies. Vehicle and MGCD516 were prepared to a final concentration of $0.5 \%$ hydroxypropyl methylcellulose (HPMC) and $0.1 \%$ Tween- 80 solution $(\mathrm{pH}$ 1.4) for xenograft studies. Both imatinib and crizotinib, purchased from LC Laboratories (Woburn, MA), were dissolved in DMSO for in vitro experiments and formulated in water for in vivo experiments.

\section{Cell lines}

Malignant peripheral nerve sheath tumor cell lines (MPNST, ST8814) were supplied by Dr. Jonathan Fletcher (Dana Farber Cancer Institute, Boston, MA). MPNST and ST8814 cell lines were authenticated as previously described [29]. Ewing sarcoma (CHP100, A673) cell lines were obtained from Dr. Melinda S. Merchant (Center for Cancer Research, NCI/NIH, Bethesda, MD). Dedifferentiated liposarcoma cell lines (LS141, DDLS) were obtained from Dr. Samuel Singer [Memorial Sloan Kettering Cancer Center (MSKCC), New York, NY], and were authenticated by gene expression profiling before distribution [45]. Synovial sarcoma cell lines (SYO-1 and HSSY-II) were obtained from Dr. Marc Ladanyi (MSKCC). Osteosarcoma cell line (Saos2) was obtained from ATCC. All cell 
lines except SYO-1 were cultured in RPMI media with $10 \% \mathrm{FBS}, 100 \mathrm{U} / \mathrm{mL}$ penicillin, and $100 \mathrm{mg} / \mathrm{mL}$ streptomycin, maintained at $37^{\circ} \mathrm{C}$ in $5 \% \mathrm{CO} 2$, and passaged for no more than 4 months. SYO-1 cell line was maintained in DME media with $10 \% \mathrm{FBS}, 100 \mathrm{U} /$ $\mathrm{mL}$ penicillin, and $100 \mathrm{mg} / \mathrm{mL}$ streptomycin, maintained at $37^{\circ} \mathrm{C}$ in $5 \% \mathrm{CO} 2$. Initial stocks of all cell lines were received from their sources within the past 3 years. Cell lines CHP100 and A673 were authenticated using RTPCR, and found to have their expected characteristic chromosomal translocations. SYO-1 and HSSY-II cell lines were authenticated by confirming the expression of the pathognomonic SYT-SSX fusion gene by RT-PCR. All cell lines were determined to be mycoplasma free via testing in the MSKCC Monoclonal Antibody Core Facility using biochemical assay MycoAlert.

\section{Cell viability assay}

Cell viability assays were carried out with the Dojindo Molecular Technologies Kit per manufacturer's instructions. Briefly, 2,000-3,000 cells were plated in 96-well plates in RPMI/DME media with 10\% FBS and then treated with the indicated drugs the next day. After 72 hours, media was replaced with $100 \mu \mathrm{L}$ of media with $10 \%$ serum and 10\% CCK-8 solution (Dojindo Molecular Technologies Kit). After 1 hour, the optical density was read at $450 \mathrm{~nm}$ using a Spectra Max 340 PC (Molecular Devices Corp.) to determine viability. Background values from negative control wells without cells were subtracted for final sample quantification. Data was plotted as $\%$ cell viability compared to DMSO (No Drug, ND) control. $\mathrm{IC}_{50}$ was extrapolated from cell viability data using CompuSyn software according to the manufacturer's instructions.

\section{Western blots}

Western blots were carried out as previously described [46]. Briefly, cell lysates were prepared by washing the cells once with sterile PBS followed by scraping in radioimmunoprecipitation assay (RIPA) lysis buffer. For xenograft tissues, lysates were prepared by cutting the snap frozen tumor tissue into a small piece and then grinding it in RIPA lysis buffer using sample grinding kit (GE Healthcare). Protein concentrations were measured using Bio-Rad protein assay dye (Bio-Rad) and equal amounts of protein (20-30 mg) were loaded on 4\%$12 \%$ gradient gels (Invitrogen) and transferred to PVDF membrane (Immobilon, Millipore) or Nitrocellulose (ThermoFisher) for the detection of phosphorylated c-Kit. After blocking with 5\% milk, membranes were probed with primary antibodies overnight at $4^{\circ} \mathrm{C}$. Bound antibodies were detected with horseradish peroxidase secondary antibodies (GE Healthcare) and visualized by enhanced chemiluminescence reagent (GE Healthcare). Antibodies for western immunoblotting were purchased from Cell Signaling Technology unless otherwise mentioned.

\section{Human phospho-RTK array}

Phospho-RTK analysis was carried out according to manufacturer's instructions (R\&D systems, ARY001B). Briefly, $1 \times 10^{6}$ cells were plated in no serum media overnight (unless otherwise indicated) in $60 \mathrm{~mm}$ plates. Next day, indicated concentrations of drugs were added in no serum media. After 3 hours of treatment, cells were stimulated using 10\%FBS containing media (no serum media was used as unstimulated control) for 1 hour. Cells were then washed once with sterile PBS, lysed in NP40 lysis buffer and approximately 200-300 $\mu \mathrm{g}$ of lysates were loaded on blocked phospho-RTK array membranes overnight. Phospho-RTK array co-ordinates can be found at www.rndsystems.com/pdf/ary001B.pdf.

\section{Gene silencing}

$50 \mathrm{nM}$ siRNAs (pooled siRNAs, Dharmacon) specific for human IGF-1R, c-Met and PDGFR $\beta$ were transfected using Lipofectamine RNAiMAX reagent (Invitrogen). Scrambled (non-targeting pool) siRNA was used as control. 48 hours after transfections, cells were trypsinized, counted using a Nexcelom cell counter and plated in 96-well plates for cell viability assays as described. Cells were also collected, lysed and analyzed by western blot to check for knockdown of protein expression.

\section{Colony assay}

1,000 cells were plated, in triplicate, onto 100 $\mathrm{mm}$ dishes and allowed to adhere overnight. Cells were treated for 24 hours with the indicated drugs. Following treatment, cells were cultured in drug-free media for 10 to 14 days. The resulting colonies were fixed in $20 \%$ ethanol and stained with $2.5 \%$ crystal violet. Colonies were scored with ColCount software from Oxford Optronix (Abingdon, UK).

\section{Xenograft studies}

Briefly, LS141 and MPNST xenografts were transplanted subcutaneously in the flank of ICR/SCID mice. Once tumors reached a volume of $80-100 \mathrm{~mm}^{3}$, the mice were randomized into different groups of 7-10 animals each and treated with the indicated drugs or vehicle control. Crizotinib was dosed at a concentration of $50 \mathrm{mg} / \mathrm{kg}$ i.p. QD, 5 days a week. Imatinib was dosed at a concentration of $30 \mathrm{mg} / \mathrm{kg}$ i.p. QD, 5 days a week. MGCD516 was dosed at a concentration of $15 \mathrm{mg} / \mathrm{kg}$ p.o. QD, 5 days a week. Tumor size was measured twice weekly by caliper. The average tumor volume in each group was expressed in cubic millimeter and calculated using the formula $\mathrm{p} / 6 \times$ (large diameter) $\times($ small diameter $)^{2}$. After 3 weeks of drug treatment, 3 animals in each group were sacrificed and the resected tumors were divided for formalin fixation (for hematoxylin/eosin 
staining and IHC) and snap frozen tissue (for western blot). Experiments were carried out under an Institutional Animal Care (MSKCC) and Use Committee-approved protocol, and institutional guidelines for the proper and humane use of animals were followed.

\section{Immunohistochemistry}

Preparation of tissue sections for IHC and staining for Ki67 was carried out by MSKCC molecular cytology core facility and has been described previously [29].

\section{Statistical analysis}

In vitro experiments were carried out at least 3 times unless otherwise indicated. Error bars shown in the graphs represent standard error. Graphs were plotted using Microsoft Excel. Statistical analyses were carried out using student's $t$-test with $95 \%$ confidence interval.

\section{ACKNOWLEDGEMENTS}

The authors would like to thank Dr. James Christensen from Mirati Therapeutics for providing the drug and helpful scientific discussions.

\section{CONFLICTS OF INTEREST}

The authors have no conflicts to disclose in relation to this work.

\section{GRANT SUPPORT}

Financial Support: P50 CA140146 (to Dr. Gary K. Schwartz).

\section{REFERENCES}

1. Forscher C, Mita M and Figlin R. Targeted therapy for sarcomas. Biologics : targets \& therapy. 2014; 8:91-105.

2. Nystrom LM, Reimer NB, Reith JD, Dang L, Zlotecki RA, Scarborough MT and Gibbs CP, Jr. Multidisciplinary management of soft tissue sarcoma. TheScientificWorldJournal. 2013; 2013:852462.

3. Clark MA, Fisher C, Judson I and Thomas JM. Soft-tissue sarcomas in adults. The New England journal of medicine. 2005; 353:701-711.

4. Cormier JN and Pollock RE. Soft tissue sarcomas. CA. 2004; 54:94-109.

5. Radaelli S, Stacchiotti S, Casali PG and Gronchi A. Emerging therapies for adult soft tissue sarcoma. Expert review of anticancer therapy. 2014; 14:689-704.

6. Daugaard S. Current soft-tissue sarcoma classifications. European journal of cancer. 2004; 40:543-548.
7. Canter RJ, Beal S, Borys D, Martinez SR, Bold RJ and Robbins AS. Interaction of histologic subtype and histologic grade in predicting survival for soft-tissue sarcomas. Journal of the American College of Surgeons. 2010; 210:191-198 e192.

8. Schwartz GK, Tap WD, Qin LX, Livingston MB, Undevia SD, Chmielowski B, Agulnik M, Schuetze SM, Reed DR, Okuno SH, Ludwig JA, Keedy V, Rietschel P, Kraft AS, Adkins D, Van Tine BA, et al. Cixutumumab and temsirolimus for patients with bone and soft-tissue sarcoma: a multicentre, open-label, phase 2 trial. The Lancet Oncology. 2013; 14:371-382.

9. Bai Y, Li J, Fang B, Edwards A, Zhang G, Bui M, Eschrich S, Altiok S, Koomen J and Haura EB. Phosphoproteomics identifies driver tyrosine kinases in sarcoma cell lines and tumors. Cancer research. 2012; 72:2501-2511.

10. Tuveson DA, Willis NA, Jacks T, Griffin JD, Singer S, Fletcher CD, Fletcher JA and Demetri GD. STI571 inactivation of the gastrointestinal stromal tumor c-KIT oncoprotein: biological and clinical implications. Oncogene. 2001; 20:5054-5058.

11. Heinrich MC, Griffith D, McKinley A, Patterson J, Presnell A, Ramachandran A and Debiec-Rychter M. Crenolanib inhibits the drug-resistant PDGFRA D842V mutation associated with imatinib-resistant gastrointestinal stromal tumors. Clinical cancer research. 2012; 18:4375-4384.

12. Dickson MA, Tap WD, Keohan ML, D'Angelo SP, Gounder MM, Antonescu CR, Landa J, Qin LX, Rathbone DD, Condy MM, Ustoyev Y, Crago AM, Singer S and Schwartz GK. Phase II trial of the CDK4 inhibitor PD0332991 in patients with advanced CDK4-amplified well-differentiated or dedifferentiated liposarcoma. Journal of clinical oncology. 2013; 31:2024-2028.

13. Krause DS and Van Etten RA. Tyrosine kinases as targets for cancer therapy. The New England journal of medicine. $2005 ; 353: 172-187$.

14. Shor AC, Agresta SV, D'Amato GZ and Sondak VK. Therapeutic potential of directed tyrosine kinase inhibitor therapy in sarcomas. Cancer control : journal of the Moffitt Cancer Center. 2008; 15:47-54.

15. Martin Liberal J, Lagares-Tena L, Sainz-Jaspeado M, Mateo-Lozano S, Garcia Del Muro X and Tirado OM. Targeted therapies in sarcomas: challenging the challenge. Sarcoma. 2012; 2012:626094.

16. Panares RL and Garcia AA. Bevacizumab in the management of solid tumors. Expert review of anticancer therapy. 2007; 7:433-445.

17. Grandinetti CA and Goldspiel BR. Sorafenib and sunitinib: novel targeted therapies for renal cell cancer. Pharmacotherapy. 2007; 27:1125-1144.

18. Hilberg F, Roth GJ, Krssak M, Kautschitsch S, Sommergruber W, Tontsch-Grunt U, Garin-Chesa P, Bader G, Zoephel A, Quant J, Heckel A and Rettig WJ. BIBF 1120: triple angiokinase inhibitor with sustained receptor 
blockade and good antitumor efficacy. Cancer research. 2008; 68:4774-4782.

19. Abraham J, Prajapati SI, Nishijo K, Schaffer BS, Taniguchi E, Kilcoyne A, McCleish AT, Nelon LD, Giles FG, Efstratiadis A, LeGallo RD, Nowak BM, Rubin BP, Malempati S and Keller C. Evasion mechanisms to Igflr inhibition in rhabdomyosarcoma. Molecular cancer therapeutics. 2011; 10:697-707.

20. Casanovas O, Hicklin DJ, Bergers G and Hanahan D. Drug resistance by evasion of antiangiogenic targeting of VEGF signaling in late-stage pancreatic islet tumors. Cancer cell. 2005; 8:299-309.

21. Ehnman M, Missiaglia E, Folestad E, Selfe J, Strell C, Thway K, Brodin B, Pietras K, Shipley J, Ostman A and Eriksson U. Distinct effects of ligand-induced PDGFRalpha and PDGFRbeta signaling in the human rhabdomyosarcoma tumor cell and stroma cell compartments. Cancer research. 2013; 73:2139-2149.

22. Chugh R, Wathen JK, Maki RG, Benjamin RS, Patel SR, Meyers PA, Priebat DA, Reinke DK, Thomas DG, Keohan ML, Samuels BL and Baker LH. Phase II multicenter trial of imatinib in 10 histologic subtypes of sarcoma using a bayesian hierarchical statistical model. Journal of clinical oncology. 2009; 27:3148-3153.

23. Butrynski JE, D'Adamo DR, Hornick JL, Dal Cin P, Antonescu CR, Jhanwar SC, Ladanyi M, Capelletti M, Rodig SJ, Ramaiya N, Kwak EL, Clark JW, Wilner KD, Christensen JG, Janne PA, Maki RG, et al. Crizotinib in ALK-rearranged inflammatory myofibroblastic tumor. The New England journal of medicine. 2010; 363:1727-1733.

24. Trivier E and Ganesan TS. RYK, a catalytically inactive receptor tyrosine kinase, associates with EphB2 and EphB3 but does not interact with AF-6. The Journal of biological chemistry. 2002; 277:23037-23043.

25. Ehnman $\mathrm{M}$ and Ostman A. Therapeutic targeting of platelet-derived growth factor receptors in solid tumors. Expert opinion on investigational drugs. 2014; 23:211-226.

26. Maki RG. Small is beautiful: insulin-like growth factors and their role in growth, development, and cancer. Journal of clinical oncology. 2010; 28:4985-4995.

27. Varkaris A, Gaur S, Parikh NU, Song JH, Dayyani F, Jin JK, Logothetis CJ and Gallick GE. Ligand-independent activation of MET through IGF-1/IGF-1R signaling. International journal of cancer. 2013; 133:1536-1546.

28. Verweij J and Sleijfer S. Pazopanib, a new therapy for metastatic soft tissue sarcoma. Expert opinion on pharmacotherapy. 2013; 14:929-935.

29. Patwardhan PP, Surriga O, Beckman MJ, de Stanchina E, Dematteo RP, Tap WD and Schwartz GK. Sustained inhibition of receptor tyrosine kinases and macrophage depletion by PLX3397 and rapamycin as a potential new approach for the treatment of MPNSTs. Clinical cancer research. 2014; 20:3146-3158.
30. Yakes FM, Chen J, Tan J, Yamaguchi K, Shi Y, Yu P, Qian F, Chu F, Bentzien F, Cancilla B, Orf J, You A, Laird AD, Engst S, Lee L, Lesch J, et al. Cabozantinib (XL184), a novel MET and VEGFR2 inhibitor, simultaneously suppresses metastasis, angiogenesis, and tumor growth. Molecular cancer therapeutics. 2011; 10:2298-2308.

31. Qian F, Engst S, Yamaguchi K, Yu P, Won KA, Mock L, Lou T, Tan J, Li C, Tam D, Lougheed J, Yakes FM, Bentzien F, Xu W, Zaks T, Wooster R, et al. Inhibition of tumor cell growth, invasion, and metastasis by EXEL2880 (XL880, GSK1363089), a novel inhibitor of HGF and VEGF receptor tyrosine kinases. Cancer research. 2009; 69:8009-8016.

32. Rixe $\mathrm{O}$ and Fojo $\mathrm{T}$. Is cell death a critical end point for anticancer therapies or is cytostasis sufficient? Clinical cancer research. 2007; 13:7280-7287.

33. Masamha CP and Benbrook DM. Cyclin D1 degradation is sufficient to induce $\mathrm{G} 1$ cell cycle arrest despite constitutive expression of cyclin E2 in ovarian cancer cells. Cancer research. 2009; 69:6565-6572.

34. Taylor BS, Barretina J, Maki RG, Antonescu CR, Singer $\mathrm{S}$ and Ladanyi M. Advances in sarcoma genomics and new therapeutic targets. Nature reviews Cancer. 2011; 11:541-557.

35. Helman LJ and Meltzer P. Mechanisms of sarcoma development. Nature reviews Cancer. 2003; 3:685-694.

36. Ho AL, Vasudeva SD, Lae M, Saito T, Barbashina V, Antonescu CR, Ladanyi $M$ and Schwartz GK. PDGF receptor alpha is an alternative mediator of rapamycininduced Akt activation: implications for combination targeted therapy of synovial sarcoma. Cancer research. 2012; 72:4515-4525.

37. Zietsch J, Ziegenhagen N, Heppner FL, Reuss D, von Deimling A and Holtkamp N. The 4q12 amplicon in malignant peripheral nerve sheath tumors: consequences on gene expression and implications for sunitinib treatment. PloS one. 2010; 5:e11858.

38. Torres KE, Zhu QS, Bill K, Lopez G, Ghadimi MP, Xie X, Young ED, Liu J, Nguyen T, Bolshakov S, Belousov R, Wang S, Lahat G, Liu J, Hernandez B, Lazar AJ, et al. Activated MET is a molecular prognosticator and potential therapeutic target for malignant peripheral nerve sheath tumors. Clinical cancer research. 2011; 17:3943-3955.

39. Fleuren ED, Hillebrandt-Roeffen MH, Flucke UE, Te Loo DM, Boerman OC, van der Graaf WT and VersleijenJonkers YM. The role of AXL and the in vitro activity of the receptor tyrosine kinase inhibitor BGB324 in Ewing sarcoma. Oncotarget. 2014; 5:12753-12768. doi: 10.18632/ oncotarget.2648.

40. Yang J, Ylipaa A, Sun Y, Zheng H, Chen K, Nykter M, Trent J, Ratner N, Lev DC and Zhang W. Genomic and molecular characterization of malignant peripheral nerve sheath tumor identifies the IGF1R pathway as a primary target for treatment. Clinical cancer research. 2011; 17:7563-7573. 
41. Becerikli M, Merwart B, Lam MC, Suppelna P, Rittig A, Mirmohammedsadegh A, Stricker I, Theiss C, Singer BB, Jacobsen F and Steinstraesser L. EPHB4 tyrosinekinase receptor expression and biological significance in soft tissue sarcoma. International journal of cancer. 2015; 136:1781-1791.

42. Mendoza-Naranjo A, El-Naggar A, Wai DH, Mistry P, Lazic N, Ayala FR, da Cunha IW, Rodriguez-Viciana P, Cheng H, Tavares Guerreiro Fregnani JH, Reynolds P, Arceci RJ, Nicholson A, Triche TJ, Soares FA, Flanagan AM, et al. ERBB4 confers metastatic capacity in Ewing sarcoma. EMBO molecular medicine. 2013; 5:1019-1034.

43. Cepero V, Sierra JR and Giordano S. Tyrosine kinases as molecular targets to inhibit cancer progression and metastasis. Current pharmaceutical design. 2010; 16:1396-1409.

44. Kumar R, Knick VB, Rudolph SK, Johnson JH, Crosby RM, Crouthamel MC, Hopper TM, Miller CG, Harrington
LE, Onori JA, Mullin RJ, Gilmer TM, Truesdale AT, Epperly AH, Boloor A, Stafford JA, et al. Pharmacokineticpharmacodynamic correlation from mouse to human with pazopanib, a multikinase angiogenesis inhibitor with potent antitumor and antiangiogenic activity. Molecular cancer therapeutics. 2007; 6:2012-2021.

45. Singer S, Socci ND, Ambrosini G, Sambol E, Decarolis P, Wu Y, O'Connor R, Maki R, Viale A, Sander C, Schwartz GK and Antonescu CR. Gene expression profiling of liposarcoma identifies distinct biological types/subtypes and potential therapeutic targets in well-differentiated and dedifferentiated liposarcoma. Cancer research. 2007; 67:6626-6636.

46. Ambrosini G, Cheema HS, Seelman S, Teed A, Sambol EB, Singer S and Schwartz GK. Sorafenib inhibits growth and mitogen-activated protein kinase signaling in malignant peripheral nerve sheath cells. Molecular cancer therapeutics. 2008; 7:890-896. 